This item was submitted to Loughborough's Research Repository by the author.

Items in Figshare are protected by copyright, with all rights reserved, unless otherwise indicated.

\title{
Beautiful and good woman: gender role negotiation among Taiwanese women who belly dance
}

\section{PLEASE CITE THE PUBLISHED VERSION}

https://doi.org/10.1080/17430437.2019.1621843

\section{PUBLISHER}

(C) Taylor \& Francis (Routledge)

\section{VERSION}

AM (Accepted Manuscript)

\section{PUBLISHER STATEMENT}

This is an Accepted Manuscript of an article published by Taylor \& Francis in Sport in Society on 4 Jun 2019, available online: https://doi.org/10.1080/17430437.2019.1621843

\section{LICENCE}

CC BY-NC-ND 4.0

\section{REPOSITORY RECORD}

Chang, Yuchi, and Alan Bairner. 2019. "Beautiful and Good Woman: Gender Role Negotiation Among Taiwanese Women Who Belly Dance”. figshare. https://hdl.handle.net/2134/37920. 


\section{Beautiful and Good Woman:}

Gender Role Negotiation among Taiwanese Women who Belly Dance

Confucian values have strongly influenced gender stereotypes in Taiwan. Although socioeconomic change and the globalization of the culture industry have contributed to the construction of modern images of women as independent, feminine and beautiful, the traditional ideal has not been totally displaced. Contrary to traditional gender expectations, the display of the female body is exceptionally encouraged in belly dancing. Utilizing data collected from 21 experienced belly dancers in Taiwan, this study examines the conflicts that women face when taking part in belly dancing, but also how they merge belly dancing with ideal gender images without conflict. The results show that, whilst few of the women experience inner conflicts, some experience external conflicts, usually with family members. However, by viewing belly dancing as a leisure exercise, a frugal and natural approach to acquiring femininity and beauty, the participants sought to differentiate themselves from the 'bad others' to construct a 'beautiful-and-good' female image. More generally, we have sought to demonstrate that critical analysis of the physically active female body must always be cognisant of the specific characteristics of those societies towards which the research is directed.

Keywords: belly dance, gender role, identity integration, stigma, Confucianism

\section{Introduction}

Confucian values have been identified as a major influence on women's participation in physical exercise in some east Asian societies (Lee 1997; Su, Yang \& Li 2013; Tsai 2006; Yeh 1995). For example, according to Lee and Zhang (2010, 211), 'before their access to today's varied leisure opportunities, Chinese women experienced millennialong powerless over their lives and fates'. The basis of gender oppression and discrimination was Confucianism's Three Obediences (to the father before marriage, the husband after marriage, and the eldest son in the case of widowhood) and Four Virtues (female morality, proper speech, modest manner, and diligent work) (Lee and Zhang 2010). Using a very specific focus - belly dancing- this paper examines the 
extent which the influence of these Confucian ideals remain influential in Taiwan which has been described by Chen $(2006,23)$, in his call for an Asian epistemological turn in social scientific research on east Asian societies, to be a 'microcosm of the region's history'.

Belly dance, also known as Middle Eastern dance, is a dance form that incorporates movements from many ancient folk and social dances of North African and Middle Eastern countries, Egypt and Turkey in particular. Belly dance steps emphasize pelvic lifts, hip rotations, chest circle and shoulder shimmies (Kraus 2014; Shay \& Sellers-Young 2005). The dance once had a strong folkloric element since people performed it at weddings, festivals and family gatherings (Hobin 2003; SellersYoung 1992; Shay \& Sellers-Young 2003). The different folk dances are often conflated in the United States and elsewhere under the single term 'belly dance', which has its origin at the 1893 Chicago World's Fair. Since then, the 'shocking' and 'indescribable' movements were promptly imitated in dance halls, vaudeville, strip clubs and burlesque houses which discredited belly dance for the next several decades (Carlton 1994; Kraus 2010ab; Shay and Sellers-Young 2003). In recent times, the dance has grown markedly as a worldwide participatory activity, in part because of its value as a form of women's exercise (Downey, Reel, SooHoo, \& Zerbib 2010).

Belly dance was introduced to Taiwan in 2002, marketed primarily as a 'body slimming exercise' with a touch of exoticism. Studies have confirmed that belly dancing has become one of the more popular leisure dances among Taiwanese women (Chang 2009; Chang 2009; Chang, Lin \& Sogawa 2017; Chen 2007; Ke 2009; Lee 2007; Tsai 2009a; Tseng 2011). According to previous studies, fitness, weight-loss and bodyshaping are the main motivations for most female participants despite their wide range of age groups and social classes. Previous research on Taiwan has shown that, in 
relation to the position of women, married or older Taiwanese women are more constrained by traditional gender expectations than their younger compatriots (Ke 2009; Lee 1997; Yeh 1995). Yet interestingly, it is they who now constitute most belly dance participants in Taiwan (Chang 2009; Lin, Yeh and Lin 2016, 71; Tseng 2011, 2).

Except for dancing in the classrooms, belly dance performances take place at a variety of Taiwanese local events, primarily because of its aesthetic feature which make it a 'performable exercise' (Chang 2009; Chang 2014). In contrast to Egypt or the United States where belly dance shows usually occur in nightclubs or ethnic restaurants, located in big cities and targeting foreign tourists (Maira 2008; Nieuwkerk 1995; Potuoglu-Cook 2006; Shay \& Sellers-Young 2003), most belly dance performances in Taiwan take place at local events and are noncommercial (Chang 2014, 90-91). However, with the beautiful two-piece costumes and the exotic flair of the dance movements attracting many women to belly dance classes, how is the resultant performance of sensual femininity interpreted when it leaves the classroom and is scrutinized by strangers' gazes? Although some studies have suggested that some female dancers are concerned about judgments from males because of the sexy body image associated with the dance (Guo 2016, 26; Yen 2013, 3), we have yet to discover if Taiwanese women experience conflicts as a result of the perceptions of others when they take part in belly dancing.

Although belly dancing in the United States and in parts of the Arab World is sometimes stigmatized because to its past (Carlton 1994; Shay and Sellers-Young 2005), relatively little is known about the situation in Taiwan. Contrary to traditional gender expectations in Taiwan about what constitutes a 'good' woman, displays of the body with an emphasis on a radically different performance of femininity are encouraged in belly dancing. Thus, the purpose of this research is to explore what 
conflicts Taiwanese women face when they take part in belly dance as a form of leisure exercise and what identity integration strategies which they use in so doing.

\section{Transforming the ideal woman in Taiwanese society}

Confucianism has traditionally had a considerable influence on many aspects of the lives of Taiwanese people. Male superiority and dominance characterize the gender ideals of Confucianism, the prevailing Han Chinese worldview and state-orthodoxy throughout Imperial China. The inferiority and subordination of women is proclaimed in dominant Han Chinese ideologies which are structurally reinforced by a strong patrilineal kinship system (Du 2011, 2, 5). The Chinese scholarly tradition has always emphasized the distinction between the sexes, arguing that each has a place and a duty within the family. From the Han dynasty, Chinese scholars and rulers developed a highly patriarchal society. Several writings were completed in the past to exemplify the model of being a good woman. The rules counseled against remarriage and excluded women from public life. Women were expected to stay at home and serve their husbands and parent-in-laws (Tamney and Chiang 2002, 130-133).

During the second half of the twentieth century, the situation of women in societies influenced by Confucianism changed dramatically. Many entered the labour market and contributed to the economic success stories of China, Hong Kong, Singapore and Taiwan (Tamney and Chiang 2002, 133-134). Yang (2008, 66-67) argues that, because of the movement of global capital, a discourse of gender equality replaced the previous discourse of domesticity. However, from the 1950s to the mid-1980s, the dominant discourse of domesticity continued to present the family as 'the foundation of Chinese tradition and morality'.

This did not mean that the earlier idea of the weak woman continued to be 
reproduced. The distinct character of Taiwanese sport nationalism under the KMT created opportunities for women to participate in sport with the China Youth AntiCommunist National Salvation Corps being the major organization for young women's sport and outdoor activities (Chiang and Bairner, 2018). At the same time, however, women's domestic roles as virtuous wives and good mothers assumed moral and political significance because of its importance to the regeneration and reproduction of the nation (Yio 2000, 11). This political view of domesticity converged with the development of the national economy with women being taught to be frugal in their management of family affairs. However, other social campaigns that had been growing since the late 1960s, such as the fight for educational equality, called for a transformation of family structures, and the rise of feminist thinking, had direct or indirect influences on the transformation of women's social roles and lives (Farris, Lee and Rubinstein 2004, 10; Yu, Liaw and Barnd 2004, 384-387). Furthermore, consumerism, capitalism, globalization and healthism also contributed to reproduce the beauty myth and new ideal femininity.

The 1990s witnessed a profound change in the Taiwanese media landscape. The KMT Central Standing Committee lifted Martial Law in 1987, and the Taiwanese public began to enjoy a greater choice of newspapers and magazines, following the abolition of restrictions on newspaper licensing and publishing (Tsai 2008, 72). Commercial advertisements, together with emerging media, made foreign products, Western life style and sexy body images seem cool to the Taiwanese people for the first time.

Yang $(2007,2011)$ asserts that the media, particularly international women's magazines, intersected with the feminist agenda in challenging the discourse of domesticity to promulgate a new form of liberated femininity which contrasted with the 
ideal of the strong but thrifty and family-oriented woman, bound by Chinese patriarchal values. Meanwhile, another subversive influence has been the rise of the beauty industry (Chang 2000; Hsieh 2004; Wang 2012).

Prior to the rapid growth of consumerism, nationalism was the most important element in the practice of leisure activities in Taiwan (Hwang 2011). Thereafter, a collective desire for consumption emerged (Lee 2011). An intensive advertising campaign by the body-beauty industry in the 1990s introduced the trends of bodyslimming and body-beauty to Taiwanese women. Most of these advertisements still reproduce a homogeneous frame of reference of body shape, size, appearance, and even life style (Chiang 2016). It was suggested that a change of body shape is a form of selfexpression, and that making oneself prettier leads to enhanced confidence (Chu 1999; Du 2003). Shaw (2012) asserts that, while a 'perfect woman' or 'ideal woman' in the past may have been the virtuous lady who took good care of her family and her domestic duties, in contemporary Taiwan, in addition to these virtues, she must also be a slender beauty who never ages and whose every body part accords with the standard size.

Although a new ideal feminine image has been created, some traditional values are still embraced by many East Asian women. Yang $(2007,365)$ argues that nowadays the image of the ideal modern women, as created by the Taiwanese and global media, is both beautiful and family-loving, rather than men haters or radical resisters to the traditional family structure. However, the appreciation of body shape is not a tradition of Chinese culture, nor was a display of sexiness/feminine charm regarded as a criterion by which to judge womanhood or the quality of being an ideal woman. Yet, no long after the lifting of Martial Law in 1987, a beautiful and sexy image of the modern woman had been created by the body-beauty industry, marking an important turningpoint in the evaluation of womanhood which would now include not only inner virtues 
but also appearance and slimness, just as in the west where the Asian-inspired yoga body came to be identified with the thin and lean media fitness aesthetic (Webb et al, 2017).

\section{It's not just dirty dancing}

Influenced by this new social atmosphere, women's leisure and exercise have become intertwined with notions of body slimming, health and sexiness in the Taiwanese media since the 1990s (Tsai 2009). Since more and more women think doing leisure dances is helpful to improve their body shape, the leisure dance/exercise industry continues to grow (Shen and Chu 2008, 3-4). Belly dance has become better known in several East Asian countries since the 1980s. Since 2002, when it was introduced to Taiwan, belly dance has usually been promoted as a beneficial form of exercise for toning one's body and as a means for enhancing women's self-confidence. In roughly a decade of development, this exotic dance had spread all over the island.

Although the precise roots of belly dance are difficult to ascertain, many scholars and writers suggest that it is rooted in ancient religions centred on female deities (AlZayer 2004; Dox 2006; Hobin 2003; Karayanni 2009; Shay 1998; Shay and SellersYoung 2005). Belly dance now tends to be viewed as a studio-taught art form worthy of dedicated and intense formal instruction with emphasis on proper posture, technique, and stage presence (Kraus 2010b).

Most Taiwanese people learn belly dancing in classes provided in dance studios and, above all, in community universities, a well-known and widespread adult education system in which housewives, middle-aged retirees and female office workers constitute the majority of the students; moreover, related workshops and competitions are held regularly every year (Chen 2007; Chu 2015; Ke 2016). Chang, Lin \& Sogawa 
(2017) argued that the close alliance between the pioneering promoters of belly dance and community universities has had considerable influence on the development of belly dance in Taiwan. In addition to helping the dance to spread quickly to local communities, it has also affected the demographics of Taiwanese belly dance participants. The relatively low registration fees in the community university system make belly dance classes affordable to women of various social classes in Taiwan. Chen's study (2007) indicates that over $70 \%$ of community universities offered belly dance classes in the second semester of 2007. Lin and Pi (2010) found in the first semester of 2009, a quarter of dance courses opened in 12 Taipei community universities are belly dance classes (52 out of 206), which reveals the high market demand. Chang (2014) showed that 82 out of 99 community universities were providing belly dance classes in the school year of 2013.

Nowadays, the majority of studies related to belly dance are conducted by Western scholars with a focus on the United States, the Middle East and North Africa. Many of these studies involve discussions of the ideologies or factors which have contributed to the changing representations of belly dance, such as colonialism, Orientalism, tourism, self-exoticism, feminism, globalization, imperialism, and postmodernism (Dougherty 2005; Dox 2006; Fisher 2003; Forner 1996; Jarmakani 2006; Maira 2008; Oatley 1999; Sellers-Young 1992; Shay and Sellers-Young 2003; Swanson 2005). While women around the world have claimed that belly dancing is beneficial to both their bodies and their minds and helps them to embrace their femininity (Christopher 2000; Crobsy 2000; Downey et al. 2010; Dox 2005; Holland 2004; Kraus 2009; Sellers-Young 2005; Stewart 2000), the femininity/sexiness of belly dance can be perceived negatively by people outside of the community. As Deagon $(2013,72)$ notes, 'The self-defining discourse of the belly dance community in the United States seeks to steer clear of slave 
markets and harem girls, focusing instead on women's community, women's history, feminine solidarity, personal enjoyment, sensual experience, cultural exchange, and artistry, often with an interlacing of goddess theology. Yet the specters of venality, marketable sexuality, and the sex business refuse to go away.' Some studies have explored strategies of identity management among Christian and Muslim women who belly dance since honoring one's body, femininity, and sensual feelings contrasts with certain religious or cultural norms of physical and sexual restraint (Buonaventura 1998; Deaver 1978; Kraus 2010b; Maira 2008).

Taiwanese academia is aware of the belly dance fever. Around twenty research papers or theses on related topics have been published in the past ten years. Before 2010, the focus of many studies was primarily on exploring the reasons why belly dance has become popular and on dancers' bodily experiences and cultural identities. Alternatively, they were preliminary discussions about the features of Taiwanese belly dance, based mainly on observation of teaching or learning (Chang 2009; Chang 2009; Chen 2007; Ke 2009; Ke 2016; Lee 2007; Tsai 2009a; Yao 2007). According to these studies, weight-loss, body-shaping, exercise, feminine charm and exotic image are the major allures for most participants.

Research topics on belly dance in Taiwan have become more diverse in recent years, some of them involving discussions on gender issues, including how gender stereotypes and masculinities affect male belly dance instructors' learning and coaching (Chen 2011) and the femininity performed in the contemporary belly dance phenomenon in Taiwan (Cheng 2018). The social, physical and psychological benefits of belly dancing have caught scholars' attention as well, benefits frequently referred to including expanding social networks and the quality of life (Chang 2011; Lin, Yeh and Lin 2016), improving self-esteem and a healthier body image of adult women (Chen 
2011; Guo 2016; Lee 2014), adolescents (Yang 2015) and women with facial disfigurements (Wang 2009; Yen 2013). Researchers have also tried to incorporate various teaching methods in the curricula of belly dance classes (Chen 2011; Tsai 2009b; Tseng 2011). Due to the ample opportunities of performing and competing, the relationship between the personalities of dancers and their repurchasing intentions of belly dance costumes has also been explored (Chu 2015).

Although various methods were adopted, and diverse viewpoints were held, all the above studies confirm that belly dance has become one of the most popular leisure dances among Taiwanese women, with participants consisting of women in different age groups.

\section{Practice, conflicts and identity integration}

In her much-acclaimed book The Beauty Myth, Naomi Wolf (1991) argues that beauty as a normative value is entirely socially constructed. In today's mass media, 'thinness' is promoted as the ideal female body image, or even the only 'pretty' body image. Methods for losing weight, body-slimming, and body-sculpting continue to show up in various kinds of media, urging women to strive for the ideal body. For the case in Taiwan, Shen and Chu $(2008,3-4)$ note that the mass media in Taiwan has been continuing to construct and represent an ideal body image that every modern woman should possess. Women unconsciously internalize these 'ideal beauty' messages and become active in seeking methods of altering their bodies so as to conform to the new social standard.

Most Taiwanese studies see the popularity of belly dance in Taiwan as a result of the globalization of the dance as well as the pursuit for modern women's ideal image inspired by western aesthetics. Chang (2009) asserted the key to its appeal to Taiwanese 
women might reside in the fact that belly dance is the best exercise for training the waist and the hips, which are the most critical area for the modern body aesthetics. Tsai (2009) argued it is ironic that weight loss and figure shaping have come to be marketed as the greatest benefits of belly dance whereas a dancer of a well-rounded body was more preferred in the origin of the dance. She argued that the influence of mainstream values of body image should not be underestimated.

While many foreign scholars adopt critical positions to examine the representations of belly dance around the world, Taiwanese studies generally speak of belly dance in a positive way, or most of them put more emphasis on exploring western influences on the representation of belly dance in Taiwan. Issues such as the conflicts or constraints resulted from local culture faced by participants have received little attention. The display of the feminine body is encouraged in belly dancing. But, in the process, women may encounter conflicts due to contradictions between the specific femininity associated with belly dance and traditional gender roles. Although globalization, consumerism, feminism, and healthism have helped to shape, and to reproduce the ideal femininity and beauty myth based on our review of the transforming of women's gender ideals in Taiwanese society, we think the legacy of Confucianism still exists.

Regardless of the type of challenges faced by some Western or Arabic belly dancers, we do not see religion a barrier to Taiwanese belly dance participants being evidenced in local studies. However, some studies mention that dancers' family members, usually from the older generation, may perceive belly dance in a negative way because of the female sexiness displayed in the dance (Guo 2016, 31; Ke 2009; Lee 2014, 62, 69-70; Lin, Yeh and Lin 2016, 74). Nonetheless the relationship between belly dancing and women's gender role ideals in Taiwan has not yet been fully explored. 
Scholars argue that identity integration is not always preceded by conflict (Lifton 1993; Manning 1999; Rodriguez and Ouellette 2000). Rather, people have a wide array of opportunities to experience various activities, and some will take advantage of these regardless of whether they easily fit together (Kraus 2010b). A variety of techniques are used to combine disparate identities; these include maintaining dual identities, selectively defining, separating roles and role salience (Mahaffy 1996; Rodriguez and Ouellette 2000; Thumma 1991; Walton 2006).

Kraus (2010a) found in the United States that, although the features of belly dancing may challenge some of their religion's beliefs, most Christian women who belly dance do not experience inner conflicts although some are concerned about potential external conflicts. For example, many western studies have discussed the discrepancy of interpretations when the dance happens in a private rather than a public venue and when the dancer performs for an audience dancer and audience (Deagon 2013; Haynes-Clark 2010; Kraus 2009; Jarmakani 2006). But at least as important is the discrepancy between how the women who belly dance feel about themselves and how they deal with the ways in which others see them. At the heart of this paper, therefore, is the dialectical relationship between bodily self-expression and externally generated pressures to conform to more traditional values.

\section{Methodology}

One of the authors entered the world of belly dance in 2006 when she took her first class in Taiwan. In the past 12 years, she had taken lessons with several instructors in Taiwan, Japan and the United States. She became a member of a collegiate Middle Eastern Dance Troupe after starting a visiting fellow program at a research institute in the United States in 2012. This immersion in the belly dance culture might bring with 
it the possibility of bias. However, as Smith and Caddick (2012, 62) argue, 'as finite human beings, we need to accept that rather than knowledge or reality being independent of the researcher's interests and purpose...they are instead dependent on us and constructed through interaction and over time'. Furthermore, given that there may be limits to reflexivity (Mauthner and Doucet, 2003), it is worth noting that the second author is a detached outsider in almost every conceivable respect.

Most of her foreign friends were very surprised to learn that many Taiwanese women do belly dance for exercise and non-paid performances. Their surprise primarily came from the impression that belly dance is very sexy whereas the stereotype of women from a society with Confucian traditions is that they tend to be more conservative in displaying sexiness. 'I didn't know Taiwanese women have become so open,' commented her American mentor after she introduced her dissertation project in their first meeting. We recognize that women who do belly dance in Taiwan may not be very open. However, such comments inspired us to explore the local representation of this globalized dance as well as the interpretation of belly dance and women's gender role ideals in Taiwan today.

The data collection for this study is part of a larger project examining the glocalisation of belly dance in Taiwan. This study draws upon participant observation, in-depth interviews and textual analysis as research methods; thematic analysis was used to code the data (Boeije 2002; Glaser and Strauss 1967). In the words of Smith and Caddick $(2012,68)$, 'thematic analysis is a method that minimally organizes and describes the data collected in detail by identifying, analyzing, interpreting and reporting patterns (i.e. themes) within data'. We found that the insider knowledge of one of the authors was a 
benefit to the research in this respect since she is familiar with the subculture of the community such as related movements, trendy styles, music, and professional dancers.

\section{Participants}

For recruiting participants of this study in 2012, we initially identified Taiwanese belly dance instructors on the internet through the website, The Taiwan Dance \& Sport Federation, and the search engine Yahoo Taiwan. Secondly, we emailed Request for Interview to them, to find out if they were interested in participating in this research study. At the same time, the instructors were asked if any of their students who would like to participate. They were then sent the Request for Interview as well.

21 Taiwanese participants aged between 30 and 62 were recruited in the end, all of them having more than three years of experience in belly dancing. Eight of the participants were belly dance instructors at the time, two of them based in central Taiwan, one based in the South, and the rest are based in Northern Taiwan. All participants belly danced at least once a week, they danced in classes and in their homes, and the vast majority had performing experiences. The description of participants is shown in Table1, names having been changed to preserve anonymity.

The interviews were conducted in August 2012. One of the authors speaks mandarin Chinese and Taiwanese as a mother tongue explained to each participant the purpose and procedure of the study and received their consent before commencing the interviews. Each interview took approximately 40-60 minutes and was conducted at the participants' places of dancing (i.e., dance studio, community center, gymnasium, school) or another location for their convenience. All the interviews were recorded and transcribed for analysis and coding. 


\section{Data and analysis}

Participant observation was undertaken in 10 institutions providing belly dance classes in Taiwan. The first phase of observation was between January 2011 and August 2012 when one of the authors was collecting data for a dissertation project. Observation was done in eight institutions where the participants of this study were teaching or learning belly dance. These institutions comprised dance studios, community universities, and lifelong learning centres across northern, central and southern Taiwan. The second phase of observation was from 2015 to 2017 in two belly dance classes in northern Taiwan where one of the authors routinely took part as a student.

The texts examined in this study mainly consist of brochures and posters published by belly dance associations and studios, syllabi of belly dance courses in community universities, newspaper articles and electronic news articles published from January 2002 to August 2017. Newspaper articles are cited from UDNDATA.COM, one of the most inclusive newspaper databases in Taiwan. Electronic news articles were searched on the website of six Taiwanese online newspapers - The Liberty Times, LT Sports, CNA News, Now News, Taiwan Review, and Yahoo News Taiwan.

\section{Findings and discussion}

The study found that people do have negative impressions of belly dance which have rarely been addressed in previous Taiwanese studies or in the Taiwanese media. Although more people have acquired an understanding of belly dance, and now perceive it in a more positive way, the negative impressions persist, and these are particularly prevalent amongst the older generation and in rural areas. Criticism about the dance usually focuses on its form as a performance rather than on doing it as exercise. 


\section{Misunderstanding on the form of performance}

In this study, we noticed that people do have negative impressions on belly dance, mainly due to its sexy and feminine image. Sonia explained her parents' attitude toward her involvement in belly dancing,

The social status of belly dancers in Egypt is very low, but we don't have that problem here, they just feel your costume is revealing, so some of them perceive it as a sultry dance.

Some of those stereotypes are still prevalent, especially among the older generation. Taking my parents for example, they knew for some time that I've been learning belly dance but they didn't tell anyone; they felt a little embarrassed, I guess. There is no problem (belly dancing) for exercise, but performance....

Brown shared his opinion on people's attitude toward belly dance based on his nineyear experience of teaching the dance,

In general, Taiwanese people are more open to belly dance compared to several years before. However, people from rural areas, especially the elderly, don't see the difference between belly dance and erotica. Many 'amusing-car' performers wear belly dance costumes even though they don't do belly dance, which gives the public a negative image of belly dance.

Frankly speaking, most men who go to belly dance performances view belly dancers with 'pornographic eyes,' they don't go there to appreciate the dance skills, it's not easy to improve the image/class of belly dance.

As mentioned before, belly dance has a long history associated with prostitution, strip clubs and burlesque houses in the Arab world and in the United States, which has left the dance with its erotic label. However, the history of belly dance in Taiwan is relatively short; it was barely known in Taiwan before 2002. When the dance initially 
came to Taiwan, some people simply regarded it as another kind of 'sexy show' that does have a long history in Taiwanese society. The inevitable result was a negative perception.

Shasha is a local of Kaohsiung, the biggest city in southern Taiwan. She experienced the later development of belly dance in Kaohsiung compared to Taipei,

The first time when my teacher and I went to the centre of a community university with the hope to open a belly dance class, their response is still vivid in my memory, the person in charge said: 'Belly dance? Come on teachers, people here are very rustic and simple.

I have to say, the development of belly dance here was two or three years behind Taipei in the beginning; people had no idea what belly dance was, only a vague (and usually negative) impression. However, the gap has narrowed down, thanks to the mass media. The number of people acknowledging belly dance as an exercise or an art form has largely increased here.

\section{Concerns, criticisms and opposition from families}

One of the authors went to a studio located in central Taiwan for participant observation in the summer of 2012. She arrived earlier than expected and settled herself on the classroom floor, waiting and stretching. One after another, students of this advanced class arrived. Some of them gathered together practicing the new choreography for a competition which was coming up the following month. Immediately before the class began, the researcher was intrigued by a conversation between the teacher and some students,

'We have to change the formation in our choreography, we missed May, she can't join the competition anymore because of the opposition from her family.' the teacher announced. 
'Will she still come to class or practice?' a student asked.

'I'm not sure, she said she needs to wait and see' the teacher replied.

This episode vividly reminds us that the life experiences of married women may still be greatly influenced or even constrained by her families. Because previous studies have revealed that marriage and family are influential in women's leisure participation (Deem 1986; Firestone and Shelton 1994; Hsieh 2003; Tsai 2006, 2008, 2009), we asked every interviewee about the attitude of their families and acquaintances towards their involvement in belly dance. It was inevitably impossible to reach those who are strongly opposed by family to belly dancing since they do not show up in the classrooms. However, by asking interviewees to share what they may have heard or seen in this connection, it was possible to explore wider, and especially negative, perceptions of belly dance from the viewpoint of dancers' families, something that has been largely neglected in previous studies. Lily shared some examples of her own students,

Some people oppose their female family members doing belly dance. It's actually not just opposition to belly dancing, they just don't want you to go out. Our society still is kind of conservative. Male chauvinism still exists, many men think 'Why does my wife have to dance in front of others?'

Some men don't allow their wives to learn dance even though their wives pay for the class by themselves. There are lots of limitations. Usually the opposition of family comes from the husband or mother-in-law, the reason we usually hear from mother-in-law is something like 'Others will gossip if my daughter in-law does this (belly dance)'

Similar to the findings of Kraus (2010b), we found that Taiwanese women tend not to experience purely internal conflicts when taking part in belly dance as leisure, but many of them have suffered as a consequence of external pressures. When reviewing Western 
literature, it is far less common to see family members preventing women from doing belly dance. But the opposition from husbands and elder relatives, especially mothersin-law, is highly significant in the case of Taiwan. We argue that this is the result of the lingering legacy of traditional gender role expectations placed upon women. Bobo is an experienced dance instructor also based in central Taiwan. He shared this observation in class,

Several moms in my class have told me not to let their husbands and family members know that they are here for belly dancing; probably they told their family they do yoga or aerobics here. Therefore, they don't buy belly dance costumes in case their family finds out. More or less a husband feels uncomfortable when his wife wears revealing clothing...

Those who are strongly constrained by their family should not be included because they won't show up in the class. Of course, I mean married women, single women don't have the same problem.

Based on the above cases, we can see that married women have more concerns and are confronted by more obstacles than younger, single women when taking part in belly dancing. In the previous section, Sonia mentioned her parents' embarrassment at her involvement in belly dancing performances while her husband took a totally supportive attitude. Similar patterns were found in other interviews. Several interviewees said that they are supported or even encouraged by their husbands to take part in belly dancing, but in order to avoid unnecessary troubles, they choose to hide this from their older relatives. Lulu an example of this,

As you know, my husband 100 percent supports me in belly dancing, for my other relatives, most of them have no idea what I am doing. I think my in-laws know that I am learning belly dance but they don't know I teach and perform.

I got my first teaching (belly dance) position several days after my grandpa passed 
away, so I told him in my mind during his memorial service, I said, 'I'm very happy now, this dance truly makes me happy, please be relieved and go with ease.'

After hearing her story, Lulu was asked, 'Did you intentionally keep it back from your older relatives?' She confirmed,

Yes. I know what's in normal people's minds (about belly dance) so I don't like to talk much about it. The older generation in particular, there is no need to make them concerned or misunderstand. I'm so tired of explaining.

Many interviewees thought the reason why people perceive belly dance in a negative way is that 'they don't understand' and because of their lack of understanding, they tend to be influenced by the sexy image of the dance and simply connect belly dance with those sexy shows in which a good woman would never get involved. So what then are the things people 'fail to understand' about belly dance?

As many Western studies have noted, feminist ideology and ancient Goddess myths are frequently adopted by dancers and even some scholars to 'sanitize' the sexy and erotic appearance of the dance (Kraus 2009b; Karayanni 2009; Maira 2008; Shay and Sellers-Young 2003). However, feminist ideas are rarely connected with belly dance in Taiwan. Moreover, few of the participants were familiar with the connection between belly dance and Goddess myth. As belly dance is often given a negative label, the next question must be how do Taiwanese women defend or explain their involvement?

Although a new ideal feminine image has been created, some traditional values are still embraced by many East Asian women. Yang (2007) argues that nowadays the image of the ideal modern women, as created by the Taiwanese media, is both beautiful and family-loving. When people raise the reputation of belly dance, various identity integration strategies are used in defense. Furthermore, most interviewees drew a line 
between the 'bad others' (those who oppose traditional gender role expectations) and themselves, with the intention of 'sanitizing' their own involvement in belly dancing.

\section{Exercise comes before performance}

As mentioned in the previous section, almost all the critiques of belly dance focus on its practice as a performance, rather than as a form of exercise. However, some people regard the once-a-week belly dance class as pure exercise, time away from family and work that is reserved for relaxation. Those participants explained that they never take part in performance since this goes against their motivation; they do not want to spend extra time and energy on preparation that might make them even more exhausted. Grace related why she does not want to perform,

I'm really bad at memorizing choreography, but our teacher never gets angry, she knows we are here just for exercise and relaxation. It's impossible for me to perform, that would make me super stressed out. I have enough at work and at home; there is no need to pay to torture myself.

In Taiwan, it is rare to hear that somebody's initial motivation to learn belly dance is to perform. Some find belly dance performance interesting and feel tempted to learn to perform, but this is still usually linked to the other motivations, exercise, body slimming and so on. Some dancers start to do group performances with classmates after learning for a while. The friendship and sisterhood derived from bonding with classmates is a very important influence on many of the participants continuing with belly dancing and trying to perform. However, performing in public is very different from dancing/performing in the classroom, especially because the audience in the latter is composed solely of familiar classmates of the same sex. Sun shares her reasons for no longer performing, 
I performed in public with my class once and that's the only time. I told my teacher I am not going to perform anymore. I don't like to be watched that way, the gaze from the male audience made me uncomfortable. I still go to belly dance class every week, that's almost the only exercise I do. I enjoy dancing for myself and dancing together with my female classmates; I don't dance for those I don't know.

In Taiwan, most belly dance students have some performance experience. However, unlike the situation in Egypt, Turkey or North America, those who engage in commercial belly dance performances or regularly take part in competitions are a small proportion of Taiwanese belly dance participants. For the majority, their performance experience comes from dancing together with their classmates in routine achievement shows held by their dance studios or community universities. Many community-based belly dance classes or groups perform frequently in this way. However, most of the performances are voluntary, and often the cost of costumes and transportation falls to the dancers themselves. Although there is a reward for commercial performance and competition winners, this is not enough to make a living so only a few people teach or perform belly dance as full-time jobs in Taiwan.

Dancing girls in the Taiwanese tradition are perceived as women who make money by dancing, entertaining and pleasing men in red-light districts. They usually have a sexy appearance, wearing heavy perfume and makeup, giving full play to their feminine charm in front of male customers. They are almost the total opposite of the traditional good women ideal. To avoid being recognized as dancing girls, therefore, many belly dance interviewees emphasized their awareness of the different attributes of other types of dancers, not least by insisting that they do not dance to make money. As Sasha shared, In my troupe, we are very careful about performance selection. We know what most people think about belly dance performance, and we can't control the attitudes of audience. We decline some invitations when they don't look so decent, 
money is not the big reason for our dancing, we do many volunteer performances, we don't live by performing belly dance.

Sasha also recalled that their troupe had encountered bad experiences in past performances when the MCs used frivolous words to introduce them. In preventing such uncomfortable situations from recurring, they began to ask to review a draft of the MC's introductory announcement before a performance, or directly appointed one of their own troupe members to act as announcer.

Critics, and the ill-informed, might wonder if those women who belly dance are simply social butterflies who enjoy flirting with men. Does performing sexiness and uncovering body parts in public enhance heterosexual attractiveness and increase the opportunities to associate with men? Based on the data collected for this study, we found women carefully differentiate themselves from social butterflies and play girls, implying they still embrace traditional virtues while pursuing a dance form that highlights a particular type of embodied femininity.

Almost every interviewee emphasized that the belly dance community is relatively secure because belly dance classes are usually for women only. In addition, although there are always males in the audience when they do performances, the women who take part in belly dance performances usually arrive and leave as a group so that it is rare for members of the audience to have any individual contact with the dancers. Ballroom dance is mentioned by many interviewees as a counter example because it usually requires a male dance partner and a lot of body contact which is thought by many Taiwanese people to be more 'serious' than exposing one's belly in public.

Based on her long-term study of the American belly dance community, Kraus (2014) suggested that belly dance has arguably become popular over time due to the myriad of benefits dancers receive from their involvement. Some dancers consider the 
dance to be an empowering path for women to become more aware of their bodies, experience sexual subjectivity, creatively express their inner feelings and emotions, and develop a feeling of 'sisterhood' and bonding with other women (Dox 2006; Moe 2012; Sellers-Young 1992). Examining Taiwanese women's experience of belly dancing, we argue that self-realization and sisterhood play particularly important roles. In the belly dance community, women usually dance with other women (or by themselves). In fact, some of them chose to do belly dance for the very reason that there is no need for male dance partners.

Belly dancing is good exercise for me. I love it and I have made many friends here. We are all women. Our dancing community is very simple. It's very different from social dance where so many troubles and affairs happen between dance partners. (Green)

If you are married, very possibly you care about your husband's feelings. In my case, I like Salsa dance and Ballroom dance very much, but they require a male dance partner and the only partner I can ask is my husband because I am not willing to dance with other males, or my husband may feel uncomfortable. For people like me, belly dance is a better choice, some of my students came to belly dance for exactly the same reason. (Fifi)

I joined a ballroom dance club in my undergrad years, but I quit later because my husband (boyfriend at the time) was unhappy that I danced with male classmates. Belly dance is different, you can even dance by yourself. Besides, I don't accept male students in my class because it's hard to tell their intentions. I want to have a 'women only' environment. (Lulu)

Many people make good friends in the belly dance community which is almost impossible for people who do ballroom dance. They always have male-female pairs and it might end up with affairs if they are not couples. (Lotus) 
Although belly dance costumes are revealing, all the interviewees in this study insisted that this does not mean they are play girls who enjoy seducing men. Neither are they radical feminists who propagate the Western ideology of body/sex liberation to rebel against patriarchal oppression (Deagon 2013; Forner 1996; Rasmussen 2005; SellersYoung 2005). From the interview excerpts above, we can see that belly dance participants have not abandoned the norms of traditional goodness, chastity and loyalty to one's partner which are still highly valued by most women in Taiwan, even though their adherence to these norms may be increasingly less conspicuous.

\section{A natural and frugal approach to achieving beauty}

People in Taiwan did not start doing exercise for fun until the 1970s and, even then, private sport centres and gyms were regarded as imported or foreign spaces (Chiu, 2003; Chiang and Bairner, 2018). When doing exercise became a fashionable lifestyle choice in urban areas, in the $1980 \mathrm{~s}$, women became the main target audience of sport and fitness centres (Chiang and Bairner, 2018). In addition, the beauty industry began to invest substantial amounts of money in a range of commercial advertisements, continuously persuading women to consume all kinds of goods (clothing, shoes, name brand, cosmetics, etc.), discipline their bodies (exercise, workout) and alter their appearance (cosmetic surgery) to get closer to the ideal images of women presented by the media. After 1990, when the antennae of the Western media stretched to Taiwan as well as other parts of east Asia (Chang and Song 2010; Johansson 2001, 95), a beautiful and sexy modern female image was created as the new ideal (Shaw 2012; Tsai 2009; Yang 2007, 2011). Women who scrupulously abide by traditional virtues such as 'frugality' (reluctance to spend any money on themselves) and 'devotion to the family' 
(lack of care about appearance and body shape after getting married or having a baby) might be seen as old fashioned, the abject other constructed by the Taiwanese media in order to contrast with the new ideal women.

As previous studies claim, most of those mature Taiwanese women who belly dance do so for exercise, body slimming and health. We argue here that this can be interpreted as an endeavour on the part of these women to approach the new ideal women image as became apparent in the interview with Lynn,

Many belly dance movements are useful for figure shaping, like figure eight for your waist curve and shimmy for your thighs. Women are really strange creatures, although we say there is no need to care too much about people's judgments, we still live under the gazes of others. If you can improve your shape without taking medicine, without starving yourself, without liposuction surgery, and see people praising you through their gaze, why not?

Besides, you don't need to spend much money, X Clinic charges you thousands of dollars for their body-slimming program, we don't need to do that, our approach is natural, economical and much healthier.

Compared with those material girls who spend extravagantly on brand names, premium cosmetics and skincare products to make them look modern and pretty, belly dance participants explain that the amount of money they spend on class registration and costumes is relatively small. Furthermore, they think they are morally victorious over artificial beauties by adopting a natural and healthy approach (dance/exercise) and exerting themselves to become prettier and more feminine through practice, rather than lazily relying on interventions from the outside - i.e. cosmetic surgeons, botox, silicone and liposuction.

In news articles related to belly dance and data collected in the interviews, it is common to find participants saying they become happier and more confident after 
learning belly dance because it helped to improve their appearance. However, despite enjoying the pleasure gained from their changed appearance, they nevertheless try to distinguish themselves from the 'modern bad others'- material girls and artificial beauties - by declaring that they still embrace traditional virtues including frugality and the appreciation of natural beauty.

\section{Conclusion}

Confucian values have strongly influenced gender stereotypes throughout east Asia over many years. According to these traditional stereotypes, women were relegated to the domestic sphere, and the ideal good woman was expected to be modest, frugal, virtuous, caring and filial. In contrast, expressing femininity, charm or beauty outside of the household was considered indecent. Women who danced in public would be described as dancing girls, i.e. members of the bad women category. Socioeconomic change in Taiwan and the globalization of the culture industry, however, have contributed to the construction of a new version of ideal images of women as independent, slim, sexy and beautiful. Yet the traditional ideal has not been totally displaced by the modern version.

The present study found that people do still have negative impressions of belly dance, which have seldom been addressed in previous Taiwanese studies and in the Taiwanese media. Criticism of the dance is usually directed at its form as a performance rather than as exercise. The negative impressions of belly dance are primarily influenced by older traditions and customs in Taiwanese society. The results of this study show that, although few of the participants experience personal internal conflicts, some of them undeniably experience external pressures which usually result from the attitudes of husbands or older relatives and with which they must wrestle. Being concerned about 
people's misunderstanding of belly dance, most belly dance participants draw a line between the 'bad others' and themselves to 'sanitize' their involvement in belly dancing. By viewing belly dancing as a leisure exercise, a frugal and natural approach to acquiring feminine beauty, interviewees differentiated themselves from dancing girls, social butterflies, play girls, material girls and artificial beauties, to construct their own 'beautiful-and-good' female image which is not completely at odds with the expectations that emanate from the persistent, albeit increasingly less overt, influence of Confucian values. More generally, we have sought to demonstrate that critical analysis of the physically active female body must always be cognisant of the specific characteristics of those societies towards which the research is directed. The frugal and natural approach feminine beauty is unlikely to be relevant to all societies although context specific research undoubtedly is.

\section{References}

AlZayer, P. 2004. World of Dance: Middle Eastern Dance. Philadelphia: Chelsea House Publishers.

Boeije, H. 2002. "A Purposeful Approach to the Constant Comparative Method in the Analysis of Qualitative Interviews." Quality and Quantity 36:391-409.

Buonaventura, W. 1998. Serpent of the Nile: Women and dance in the Arab world. New York, NY: Interlink.

Carlton, D. 1994. Looking for little Egypt. Bloomington, Indiana: IDD Books.

Chang, C. H. 2000. "Weight-Loss Advertisements in Taiwan from 1982 to 1999-A multiperspective approach." The Journal of Advertising Research 15:67-114.

Chang, K. S. and Song, M. Y. 2010. "The Stranded Individualizer under Compressed Modernity: South Korean Women in Individualization without Individualism." The British Journal of Sociology 61(3): 539-564.

Chang, S. L. 2011. "Comparison of Different Exercises on the Physical Fitness and Quality of Life of Middle Aged Women." Journal of Physical Education Fu Jen Catholic University 10:115-133

Chang, X. H. 2009. "Glamorous dance in Taiwan-Two myths of women body." Forum in Women's and Gender Studies 90: 2-3.

Chang, Y. C. 2014. Exotic image, healthy exercise, modern beauty and traditional virtue: The glocalization of Belly Dance in Taiwan (Unpublished doctoral dissertation). Waseda University, Tokyo, Japan.

Chang, Y., Lin, P. H. \& Sogawa, T. 2017. "Belly dancing as exercise: image-building of a foreign dance in Taiwan." Asia Pacific Journal of Sport and Social Science 
6(1): 34-45. DOI: 10.1080/21640599.2017.1286107.

Chang, Z. H. 2009. "New Trend of Taiwan Leisure Exercise: A Study of the development of Middle Eastern Dance." Journal of Physical EducatioNational Taipei University of Education 3:72-80.

Chen, C. C. 2011. A Study of the Body Experience in Middle Eastern Belly Dance Infusion Curriculum -A Case Study in Wanhua Community College. (Unpublished Master's Thesis) National Chi-Nan University, Nantou.

Chen, C. H. 2011. Sports and Gender Stereotypes: A Case Study of Male Belly Dance Instructors. (Unpublished Master's Thesis) National Taiwan Sport University, Taoyuan.

Chen, G. X. 2006. Deimperialism; taking an Asian methodological turn. Taipei: Editions du Flaneur.

Chen, S. L. 2007. "A study on the current state of Belly Dancing's development in Taiwan." Retrieved July 15, 2016, from http://lucybd.xxking.com/ShowArticle.asp?menu=show_article\&cate_ser= 36\&article_ser $=240$

Cheng, F. T. 2018. "Towards A Florid Critique: An Interpretation of the Contemporary Belly-dance Phenomenon in Taiwan." Journal of Women's and Gender Studies 42:39-71

Chiang, Y. (2016). The contradictory complex between women and sport. [ Online forum comment], 11 October. Retrieved from http:// twstreetcorner.org/2016/10/11/ying-chiang/

Chiang, Y. and Bairner, A. 2018. Women, Sport and the Politics of Gender in Taiwan. In G. Molnar, S. N. Amin, and Y. Kanemasu (Eds.), Women, Sport and Exercise in the Asia-PacificRegion: Domination-Resistance-Accommodation, (pp. 21-36). London, Routledge.

Chiu, C. C. 2003. The cultural study of recreational fitness and lifestyle, Unpublished Master's Thesis, National Taiwan Normal University, Taipei.

Christopher, Z-H. 2000. "The Emergence of the New Sacred Temple Priestess." Habibi 18(2):46-51.

Chu, C. C. 2015. The Relation of Personality of bellydancers to the Design Satisfaction and Repurchase Intentions. (Unpublished Master's Thesis) Tainan University of Technology, Tainan.

Chu, P. I. 1999. "Research on technology and medical history in Taiwan: An analysis on the knowledge groups in modern Taiwan." Journal of the Institute of Taiwan History, Academia Sinica 4(2): 157-174.

Crobsy, J. 2000. The goddess dances: Spirituality and American Women's interpretations of middle eastern dance. In W. Griffin (Ed.), Daughters of the goddess: Studies of healing, identity and empowerment (pp. 166-182). New York, NY: Rowman \& LittleField Publishers.

Deagon, A. 2013. "The Golden Mask: Tipping the Belly Dancer in America." Feminist Studies 9(1): 71-97.

Deaver, S. 1978. "Concealment vs. display: The modern Saudi woman. Dance Research Journal." 10: 14-18.

Deem, R. 1986. "All work and no play?” The sociology of women and leisure. Milton Keynes eds., Great Britain: Open University Press.

Dougherty, R. 2005. "Dance and the Dancer in Egyptian Films." Belly Dance: Orientalism, Transnationalism and Harem Fantasy. Anthony Shay and Barbara Sellers-Young, eds., 145-171. Costa Mesa, California: Mazda Publishers.

Downey, D. J., Reel, J. J., SooHoo, S., and Zerbib, S. 2010. "Body image in Belly 
Dance: Integrating alternative norms into collective identity." Journal of Gender Studies, 19: 377-393.

Dox, D. 2005. Spirit from the body: Belly Dance as a spiritual practice. In A. Shay \& B. Sellers-Young (Eds.), Belly dance: Orientalism, transnationalism and harem fantasy (pp. 303-340). Costa Mesa, California: Mazda Publishers.

Dox, D. 2006. "Dancing around Orientalism." The Drama Review 50:52-71.

Du, S. 2011. Women and gender in contemporary Chinese societies : beyond Han patriarchy. Lanham, Md. : Lexington Books.

Du, Y. R. 2003. Who's talking women's body? Take body-slimming TV advertisements for example. (Unpublished Master thesis). National Chengchi University, Taipei.

Farris, C. S., Lee, A. and Rubinstein, M. A. 2004. Women in the new Taiwan : gender roles and gender consciousness in a changing society. Armonk, N.Y. : M.E. Sharpe.

Firestone, J. and Shelton, B. A. 1994. “A comparison of women's and men's leisure time: Subtle effects of the double day." Leisure Science 16: 45-60.

Fisher, J. M. 2003. Orientalism, Representation and Created Fantasies: The Transformation of Traditional Middle Eastern Dances to Belly Dance (Unpublished master's thesis). Florida Atlantic University, Florida.

Forner, M. L. 1996. The Transmission of Oriental Dance in the United States: From Raqs Sharqi to Belly Dance. (Unpublished master's thesis). University of California, California.

Glaser, B. G. and Strauss, A. L. 1967. The Discovery of Grounded Theory: Strategies for Qualitative Research. Chicago: Aldine.

Guo, R. W. 2016. A Study on the Participatory processes and Body Image of Belly Dancers. (Unpublished master's thesis). National University of Tainan, Tainan.

Haynes-Clark, J. L. 2010. American Belly Dance and the invention of the new exotic: Orientalism, feminism, and popular culture (Unpublished Master's thesis). Portland State University, Oregon.

Hobin, T. 2003. Belly Dance: The dance of mother Earth. London: Marion Boyars. Holland, S. 2004. Alternative feminities: Body, age, and identity. Oxford: Berg.

Hsieh, C. M. 2004. "The Legend of Meidonfon: From a Electronic Factory Labor to The Body-Slimming Queen-Ya-Ching Chuang." Business Today 393. Retrieved from http://www.businesstoday.com.tw/

Hsieh, S. F. 2003. "A study on the relationship among gender, family life cycle, family leisure participation frequency, and leisure constraints." Tourism Management Research 3 (1): 1-21.

Hwang, J. L. 2011. History, body and nation/state: the formation of body in modern China, 1895-1937. Taipei: Linking.

Jarmakani, A. 2006. Belly Dancing for liberation: A critical interpretation of reclamation rhetoric in the American Belly Dance community. In D.A. Zabel (Ed.), Arabs in the Americas: Interdisciplinary essays on the Arab Diaspora (pp. 145-168). New York, NY: Peter Lang.

Johansson, P. 2001 "Selling the Modern Woman: Consumer Culture and Chinese Gender Politics." Images of the Modern Woman in Asia: Global Media, Local Meanings, Shoma Munshi eds. Richmond, Surrey: Curzon.

Karayanni, S. S. 2009. "Sacred Embodiment: Fertility, Ritual, Mother Goddess, and Cultures of Belly Dance." Religion and the Arts 13: 448-463.

Ke, Y. C. 2009. "Participant motivation and cultural identity in belly dancing: A case study of a community in Shitwen district of Taichung city." Dance Education 9: 63-71.

Ke, Y. C. 2016. "A Study of Participation Motivation and Culture Identity of Belly 
Dancers in Taichung City." Journal of Physical Education and Leisure, Ling Tung University 14:75-90.

Kraus, R. 2009. "Straddling the sacred and secular: Creating a spiritual experience through Belly Dance." Sociological Spectrum 29: 598-625.

Kraus, R. 2010a. "We are not strippers: How Belly Dancers manage a (soft) stigmatized serious leisure activity." Symbolic Interaction 33: 435-455.

Kraus, R. 2010b. "They danced in the Bible: Identity integration among Christian women who Belly Dance." Sociology of Religion 71: 457-482.

Kraus, R. 2014. "Becoming a belly dancer: gender, the life course and the beginnings of a serious leisure career. Leisure Studies 33(6): 565-579. DOI:

$10.1080 / 02614367.2013 .833284$

Lee, B. and Zhang, A. 2010. Women's leisure and leisure satisfaction in contemporary urban China. World Leisure Journal 3: 211-221.

Lee, C. Y. 2014. A Study of the Experience of Learning Bellydance of Four Females. (Unpublished Master's Thesis) Chinese Culture University, Taipei.

Lee, P. C. 2007. "A study on Belly Dance development." Journal of Internet Sociology 65. Retrieved July 15, 2016 from http://www.nhu.edu.tw/ society/e-j/65/65-03.htm

Lee, S. H. 1997. "Urban Women Leisure Patterns and Constraints" Outdoor Recreation Research 10(1):43-68

Lee, Y. Y. 2011. Consumption and Daily Life. In Y. H. J. (Ed.), The history of Republic of China (pp. 589-619). Taipei, Taiwan: National Chengchi University

Lin, C. J., Yeh, T. M. and Lin, Y. L. 2016. "Exercise and Leisure! The Effect of Belly Dance Participants' Leisure Involvement on Leisure Benefits." Journal of Sport, Leisure and Hospitality Research 11(3):57-59.

Lin, H. H. and Pi, L. L. 2010. "Categories of Dance Courses of Taipei City Community Universities" Sports Research Review 107:8-16.

Lifton, R. J. 1993. The Protean Self: Human Resilience in an Age of Fragmentation. Chicago: University of Chicago Press.

Maira, S. 2008. "Belly Dancing: Arab-Face, Orientalist Feminism, and U.S. Empire." American Quarterly 60(2): 317-345.

Manning, C. 1999. God Gave us the Right: Conservative Catholic, Evangelical Protestants, and Orthodox Jewish Women Grapple with Feminism. New Brunswick:Rutgers University Press.

Mahaffy, K. A. 1996. "Cognitive Dissonance and Its Resolution: A Study of Lesbian Christians." Journal for the Scientific Study of Religion 35:392-402.

Mauthner, N. S. and Doucet, A. 2003. "Reflexive Accounts and Accounts of Reflexivity in Qualitative Data Analysis." Sociology, 37: 413-431.

Moe, A. A. 2012. "Beyond the Belly: An Appraisal of Middle Eastern Dance (aka Belly Dance) as Leisure." Journal of Leisure Research 44(2): 201-233.

Nieuwkerk, K. V. (1995). A Trade Like Any Other: Female Singers and Dancers in Egypt. Austin : University of Texas Press.

Oatley, D. 1999. "Staging Unstable Bodies: The Practice of Oriental Dance in the West within the Context of the Postmodern." Habibi 17(4): 18-21.

Potuoglu-Cook, O. (2006). "Beyond the Glitter: Belly Dance and Neoliberal Gentrification in Istanbul." Cultural Anthropology 21(4): 633-660.

Rasmussen, A. 2005. "An evening in the orient." In A. Shay \& B. Sellers-Young (Eds.), Belly Dance: Orientalism transnationalism and harem fantasy (pp. 172-206). Costa Mesa, California: Mazda Publishers. 
Rodriguez, E. M. and Ouellette, S. C. 2000. "Gay and Lesbian Christians: Homosexual and Religious Identity Integration in the Members and Participants of a Gay-positive Church." Journal for the Scientific Study of Religion 39:333-47.

Sellers-Young, B. 1992. "Raqs E1 Sharqi: Transculturation of a Folk Form." Journal of Popular Culture 26(2): 141-152.

Sellers-Young, B. 2005. "Body, image, identity: American tribal Belly Dance." In A. Shay and B. Sellers- (Eds.), Belly Dance: Orientalism, transnationalism and harem fantasy (pp. 277-303). Costa Mesa, California:Mazda Publishers.

Shaw, P. 2012. "Gender and the media." In Huang, S. L. \& Yu, M. H. eds. Gender dimensions in Taiwanese society. Taipei: Juilio, pp. 87-106.

Shay, A. 1998. "Danse du ventre." In S.J. Cohen, \& Dance Perspectives Foundation (Eds.), International encyclopedia of dance: A project of dance perspectives foundation (Vol. 2, pp. 344-346). New York, NY: Oxford University Press.

Shay, A., and Sellers-Young, B. 2003. "Belly dance: Orientalism; exoticism: Self-Exoticism." Dance Research Journal 35: 13-37.

Shay, A. and Sellers-Young, B. 2005. "Introduction". In Anthony Shay and Barbara Sellers-Young, eds., 1-27. Belly Dance: Orientalism, Transnationalism and Harem Fantasy. Costa Mesa, California: Mazda Publishers.

Shen, R. G. and Chu, B. H. 2008. "A Study on Tainan's Female Consumers' Course Requirements towards Leisure Dance.” Journal of Sports Knowledge 5: 185-199.

Smith, B and Caddick, N. 2012. "Qualitative methods in sport: a concise overview for guiding social scientific sport research." Asia Pacific Journal of Sport and Social Science 1: 60-73.

Stewart, I. 2000. Sacred Women, Sacred Dance: Awakening Spirituality through Movement \& Ritual. Rochester, Vermont: Inner Traditions.

Su, M. J., Yang, I. H. and Li, S. Y. 2013. "A Study on Constraint Factors of Leisure Sports for Married Women in Taiwan" Journal of Sport and Recreation Research $8(2): 41-67$.

Swanson, L. 2005. “They Said She Could Dance on a Single Tile.” Belly Dance: Orientalism, Transnationalism and Harem Fantasy. Anthony Shay and Barbara Sellers-Young, eds., 342-350. Costa Mesa, California: Mazda Publishers.

Tamney, J. B., and Chiang, L. H. 2002. Modernization, globalization, and Confucianism in Chinese societies. Westport, Conn.: Praeger.

Thumma, S. 1991. "Negotiating a Religious Identity: The Case of the Gay Evangelical." Sociological Analysis 52:333-47.

Tsai, C. T. 2006. "The Influence of Confucianism on Women's Leisure in Taiwan." Leisure Studies 25(4): 469-476.

Tsai, C. T. 2008. “The Women's Movement and Women's Leisure in Taiwan.” World Leisure Journal 50(1): 70-78.

Tsai, C. T. 2009. "Media systems and their effects on women's sport participation in Taiwan." Sport, Education and Society 14(1): 37-53.

Tsai, S. Z. 2009a. "Sexy Dancer or Generative Goddess." Forum in Women 's and Gender Studies 90: 4-14.

Tsai, S. Z. 2009b. "Don't Want to call it Belly Dance: Designing a Physical Education Curriculum Corresponding to Teaching Philosophies of Community University." Forum in Women's and Gender Studies 91:93-104

Tseng, S. L. 2011. The Action Research of Integrating Somatic Movement Education into Belly Dance Instructions. (Unpublished Master's Thesis) National Taitung University, Taitung.

Walton, G. 2006. "Fag Church: Men Who Integrate Gay and Christian Identities." 
Journal of Homosexuality 51:1-17.

Webb, J. B., Vinoski, E. R., Warren-Findlow, J., Padro, M. P., Burrie, E. N., and Suddreth, E. M. 2017. "Is the 'Yoga Bod' the new skinny?: a comparative content analysis of mainstream yoga lifestyle magazine covers." Body Image, 20:87-98.

Wolf, N. 1991. The beauty myth: How images of beauty are used against women (1st ed.). New York: W. Morrow.

Wang, M. J. 2012. "Meidonfon: The Better Service makes Treatments as Vacation." Global Views Monthly Special Issue-The Consuming Trend of 2012. Retrieved from http://www.gvm.com.tw/Boardcontent_19773.html

Wang, P. S. 2009. Representing Beauty: The Meaning and Changes of the Process of Belly-Dance Performance by Burn Survivors and People with Facial Disfigurement. (Unpublished Master's Thesis) Soochow University, Taipei

Yang, F. C. 2007. "Beautiful-and-bad woman: Media feminism and the politics of its construction." Feminist Studies 33(2): 361-383.

Yang, F. C. 2008. "Engaging with Korean dramas: Discourses of gender, media, and class formation in Taiwan." Asian Journal of Communication 18(1): 64-79.

Yang, F. C. 2011. "Constructing shou-nyus' identity and desire: The politics of translation in Taiwanese sex and the city." International Journal of Cultural Studies 14(3): 235-249.

Yang, J. L. 2015. Impact of Belly Dance Learning on the Body Image and Physical Mental Health for the Adolescences. (Unpublished Master's Thesis) Chinese Culture University, Taipei.

Yao, R. T. 2007. A Study of the Bodily Experiences of Belly Dance. (Unpublished Master's Thesis) Chungyuan University, Taoyuan.

Yeh, C. K. 1995. "Women Rights and Women's Leisure" Outdoor Recreation Research 8(3):1-14

Yen, C. J. 2013. Brilliant Phoenix Dancing in Spring --The Construction of the Facial Disfigurement Women's Body Image and Meaning of Life by the Performance of Belly Dance. (Unpublished Doctoral Thesis) National Sport University, Taoyuan.

Yio, C. 2000. Protecting adopted daughters movement in the 1950s: Adopted daughters, women's work, and the home/nation. (Unpublished Master's Thesis) National Tsing Hua University, Hsinchu.

Yu, C. C., Liaw, Y. H., and Barnd, S. 2004. "Cultural and social factors affecting Women's physical activity participation in Taiwan." Sport, Education and Society 9:379-393. 